\title{
Lethal midline lymphoma causing acute dacryocystitis
}

\author{
D. J. SPALTON, P. J. O'DONNELL, AND E. M. GRAHAM
}

From the Medical Eye Unit, St Thomas's Hospital, London SE1

SUMMARY A case of fatal midline lymphoma in a young woman is described and the pathology is discussed. The gross nasopharyngeal necrosis led to nasolacrimal duct obstruction and acute dacrocystitis.

'Midline lethal granuloma' or 'nonhealing midline granuloma' is a rare and dramatic condition causing progressive ulceration and destruction of the nasopharynx, nose, and face and the demise of the patient from a disfiguring and most unpleasant illness. The differential diagnosis covers a wide spectrum of inflammatory and neoplastic diseases, but there are a group of patients where no precise diagnosis is made. The pathology of this group has recently been clarified ${ }^{1}$ and the diagnosis of midline granuloma is no longer universally accepted. ${ }^{2}$ Many of these previously undiagnosed lesions have been shown to have a lymphomatous origin, ${ }^{3}$ and an appreciation of this has rationalised their therapy, which had previously been based on the clinical response to steroids, cytotoxic drugs, or radiotherapy. We report the case and pathology of a patient with a midline lymphoma that was fatal. During the course of her illness she developed acute dacryocystitis, which was a considerable management problem for the ophthalmologists.

\section{Case report}

A 27-year-old Turkish Cypriot woman presented with a 6-month history of pain in her nose and a dirty discharge from it. For the last 3 months she had had an excruciatingly painful throat and mucus catarrh which made it so difficult to eat solids that she had lost 2 stone $(12.7 \mathrm{~kg})$ in weight in the previous 7 weeks. Since her symptoms started her hearing had not been so good, but she was otherwise well. She did not smoke and had no relevant previous medical history apart from some mild asthma in the past. She had lived in England for 15 years.

On examination there was a purulent nasal discharge and ulceration of the soft palate. She was

Correspondence to Mr D. J. Spalton, FRCS, Eye Department, Charing Cross Hospital, Fulham Palace Road, London W6 admitted to hospital on 17 December 1979 for further investigations. These showed $\mathrm{Hb} 10.9 \mathrm{~g} / \mathrm{dl}$, leucocytes $5.0 \times 10^{9} / 1$ (neutrophils $67 \%$, toxic granulation observed); erythrocyte sedimentation rate (ESR) 65 $\mathrm{mm} / \mathrm{h}$. Blood urea was $2.7 \mathrm{mmol} / \mathrm{l}$, proteins $67 \mathrm{~g} / \mathrm{l}$ (albumin $34 \mathrm{~g} / \mathrm{l}$ ); liver function tests and serology for syphilis were normal. Immunological tests showed raised levels of $C_{3} 2 \cdot 2 \mathrm{~g} / 1(0.57-2 \cdot 1)$ and $C_{4} 0.78 \mathrm{~g} / \mathrm{l}$ $(0 \cdot 15-0 \cdot 44)$, with normal $\mathrm{CH}_{50}$ and alternative pathway. Chest and sinus $x$-rays were clear.

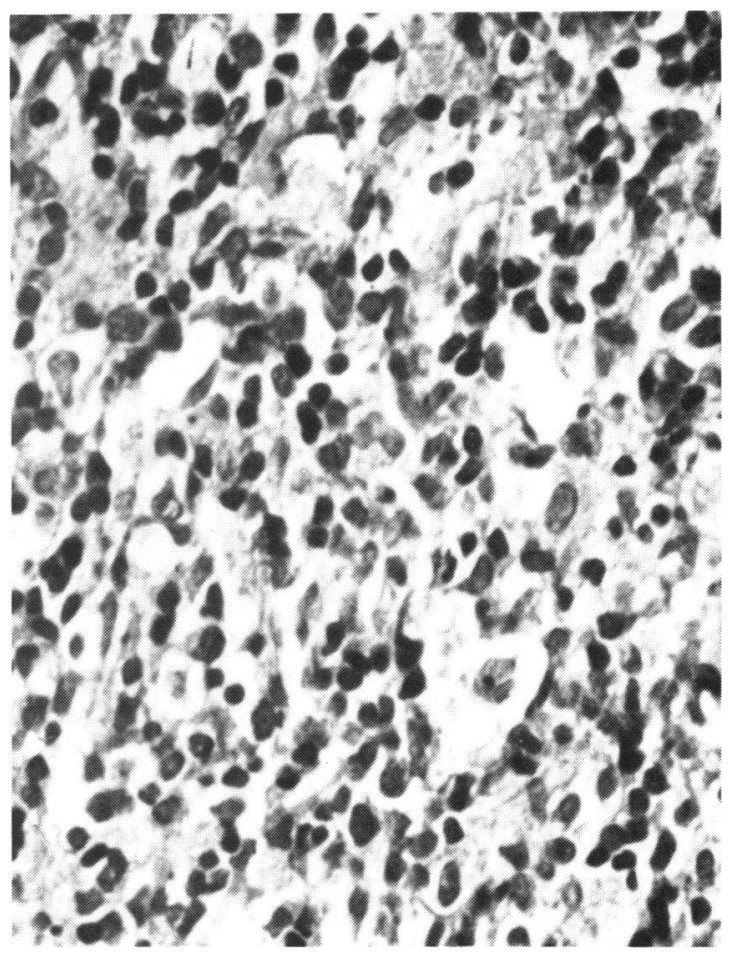

Fig. 1 High-powered view of the biopsy of the pharyngeal lesion showing a pleomorphic lymphoid infiltrate. 


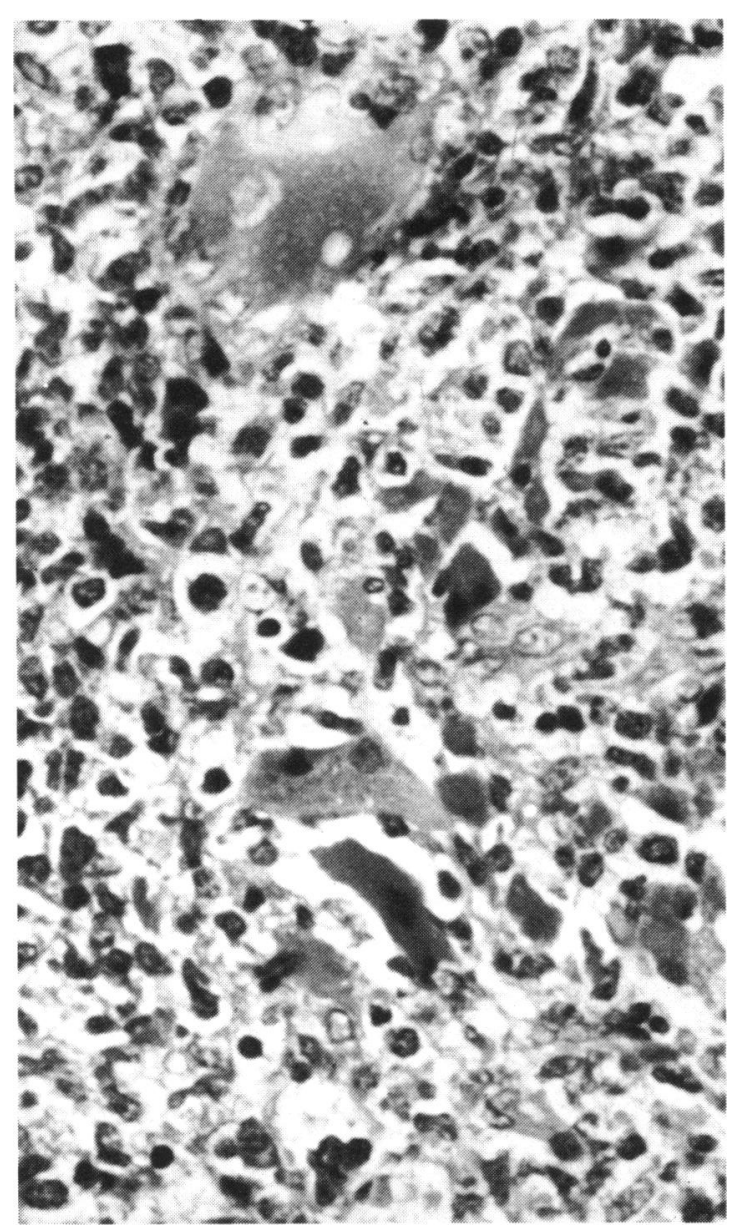

Fig. 2 Some areas of the same biopsy as in Fig. 1 had a granulpmatous component.

Examination under anaesthesia soon after admission revealed a large central ulcer on the fixed soft palate spreading down the left hand side of the pharynx to the lower limit of the tonsillar fossa, with some swelling into the posterior nasal space above on the left. Biopsy specimens showed ulceration of nonkeratinising stratified squamous epithelium, with infiltration by lymphocytes, plasma cells, plasmacytoid lymphocytes, histiocytes, and neutrophil polymorphs. Special stains for treponemata were negative. The appearances were thought to be those of a nonspecific active chronic inflammation. Virus cultures from the ulcer were negative. Major aphthous ulceration was diagnosed, and she was initially treated with steroid sublingual pellets and tetracycline mouth washes.

There was no improvement, and the condition of

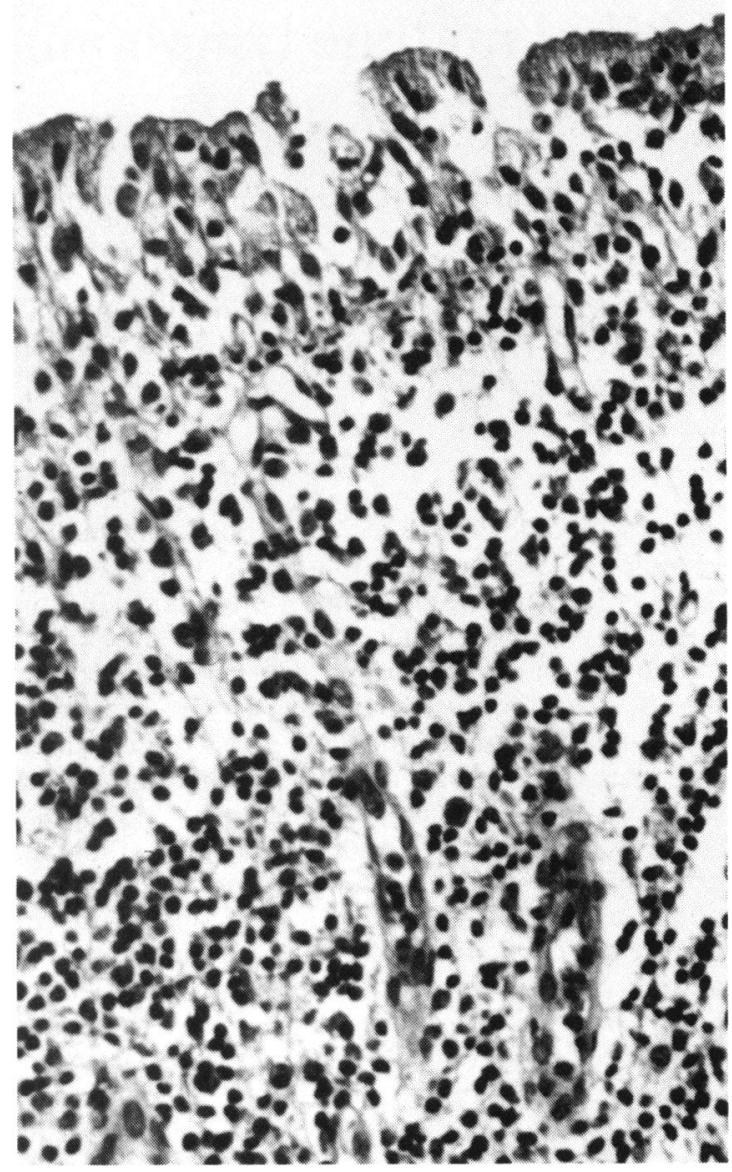

Fig. 3 Biopsy of the nasal mucosa showing respiratory epithelium with a pleomorphic lymphoid infiltrate.

her nasopharynx deteriorated. A repeat biopsy was performed on 15 January 1980, and this showed similar features to the previous biopsy. Deeper levels were cut on this material and showed a polymorphic inflammatory infiltrate in which there were occasional ill defined granulomata consisting of lymphocytes and epitheloid histiocytes (Figs. 1 and 2). There was no evidence of vasculitis. A biopsy of the nasal mucosa taken at the same time showed necrotic eosinophilic material with chronic inflammatory cells and severely inflamed granulation tissue (Fig. 3). At this stage it was thought possible that the pathological appearances might support a diagnosis of Wegener's granulomatosis, though there was no evidence of necrotising vasculitis or giant cell formation.

The patient was started on prednisolone $40 \mathrm{mg}$ /day and cyclophosphamide $120 \mathrm{mg} /$ day. However, she 


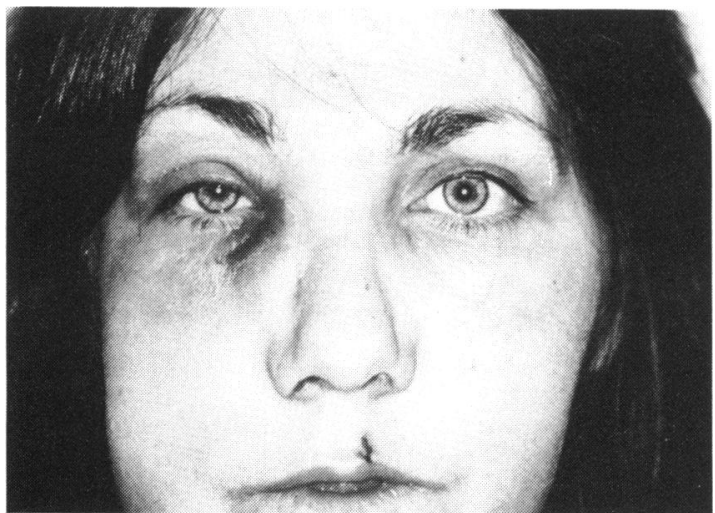

Fig. 4 The patient with acute right dacryocystitis.

did not improve and rapidly developed a severe pancytopenia and pyrexia. Blood cultures were negative, but systemic antibiotics were started, and the dosage of cyclophosphamide was reduced to $60 \mathrm{mg} /$ day.

At the beginning of February 1980 she developed a florid acute dacryocystitis which became fluctuant over several days and was drained through the skin (Figs. 4 and 5). Little else could be done, as her nose was completely blocked with necrotic tissue. Facial $x$-rays now showed opaque sinuses with fluid levels.

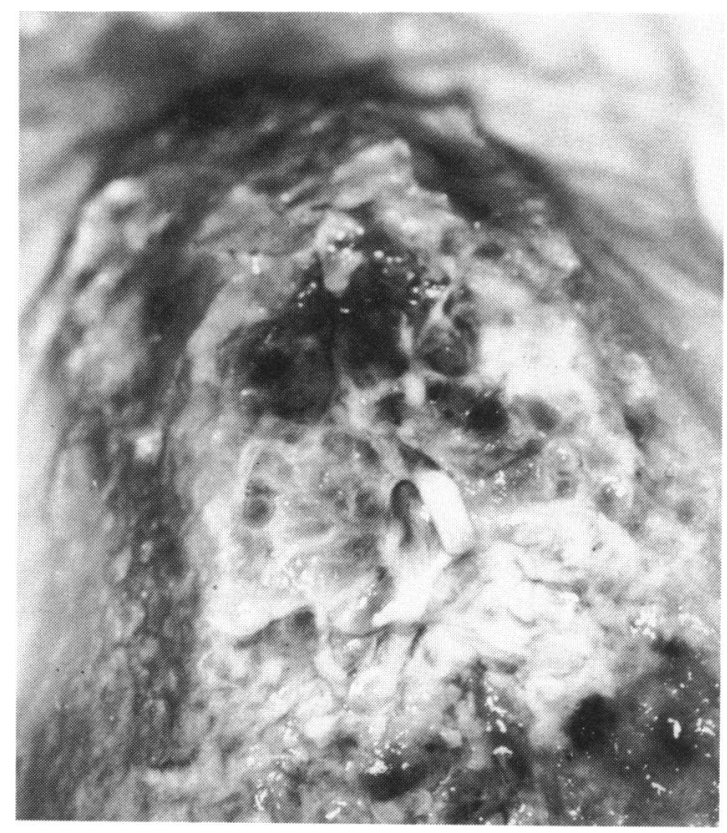

Fig. 5 The palate. The teeth and gums are at the top of the photograph. There is gross tissue destruction and ulceration of the hard and soft palate.
She developed proteinuria and her condition further deteriorated.

The pathology was reviewed once again, and in retrospect it was decided that the inflammatory exudate was so pleomorphic, diffuse, and destructive that the appearances were those of a poorly differentiated lymphoma. Bone marrow aspiration was undiagnostic but a CT scan showed moderate enlargement of the liver and spleen without evidence of para-aortic gland enlargement. On 21 February radiotherapy to the nasopharynx was started. She had 2 episodes of bleeding from her mouth, and 4 days later she developed an acute haemorrhage from a tonsillar artery, became asphyxiated, and died. Permission for necropsy was refused.

\section{Discussion}

Destructive midline nasopharyngeal lesions can be divided into those with an inflammatory aetiology and those that have a more malignant behaviour. Michaels and Gregory ${ }^{3}$ reviewed 30 cases with destructive lesions of the nasal passages. From this group 17 patients had purely inflammatory lesions (including 11 with Wegener's granulomatosis) and 3 had definite lymphomas. The remaining group of 10 patients had similar pathology, and they reviewed these patients in detail. The pathology was characterised by a necrosis with an atypical cellular exudate, cytological features suggesting malignancy, evidence of local invasion and destruction in some patients, and, in 4 patients, evidence of systemic spread. They concluded that the lesion was a form of malignant histiocytic lymphoma and that radiotherapy was the treatment of choice. The pathology in our patient would appear to fit this category of midline lymphoma. Clinical evidence that systemic spread had occurred is suggested by the hepatosplenomegaly that developed in the later stages of her illness, although no tissue from these organs was examined.

Acute dacryocystitis almost invariably results from obstruction of the nasolacrimal duct with stasis in the sac and infection, probably originating from the nose, as acute dacryocystitis occurring concurrently with bacterial conjunctivitis is rare. The accepted treatment is to give heat and antibiotics and to await the localisation of pus, percutaneous drainage if necessary, and reconstruction of the lacrimal drainage system by dacryocystorhinostomy when the inflammation has subsided. Occasionally the lacrimal sac can be obstructed by a specfic disease such as tuberculosis, or a tumour in the sac or nasal cavity.

The major problem in the management of this patient was the gross amount of necrotic tissue in the nasopharynx causing secondary infection and septicaemia. Her treatment was complicated by pan- 
cytopenia which came on within days of starting the steroids and cyclophosphamide and was probably due to bone marrow depression from a combination of drugs, infection, and possibly the primary disease process. In this situation little could be done for her acute dacryocystitis apart from draining pus percutaneously to alleviate the discomfort.

\section{References}

1 Shanmugaratnam K, Sobin LH. Histological typing of upper respiratory tract tumours. WHO International Classification of Tumours. 1978: no. 19, paras. 48, 82, 83.

2 Editorial. Non-healing (midline) granuloma. Lancet 1977; i: 1296-7.

3 Michaels L, Gregory MM. Pathology of non-healing (midline) granuloma. J Clin Pathol 1977; 30: 317-27. 